Seeman, P. (1972) Pharmacol. Rev. 24, 583-655.

Shimshick, E. J., \& McConnell, H. M. (1973) Biochemistry 12, 2351-2360.

Sklar, L. A., Hudson, B. S., \& Simoni, R. D. (1977) Biochemistry 16, 819-823.

Smith, R., \& Tanford, C. (1973) Proc. Natl. Acad. Sci. U.S.A. 70, 289-293.

Steck, T. L. (1974) J. Cell Biol. 62, 1-19.

Steinemann, A., Stark, G., \& Läuger, P. (1972) J. Membr. Biol. 9, 177-194.

Sturtevant, J. M. (1982) Proc. Natl. Acad. Sci. U.S.A. 79, 3963-3967.
Swanson, P. E., Paddy, M. R., Dahlquist, F. W., \& Storm, D. R. (1980) Biochemistry 19, 3307-3314.

Tanford, C. (1973) The Hydrophobic Effect, Wiley, New York.

Tse-Tang, M. W., Gaffney, B. J., \& Kelly, R. E. (1980) Heterocycles 15, 965-974.

Waggoner, A. P. (1979) Annu. Rev. Biophys. Bioeng. 8, $47-68$.

Willingham, G. L., \& Gaffney, B. J. (1983) Biochemistry (following paper in this issue).

Zantour, H., Pousse, A., \& Brini, M. (1972) Bull. Soc. Chim. Fr., 4715-4722.

\title{
Reactions of Spin-Label Cross-Linking Reagents with Red Blood Cell Proteins $^{\dagger}$
}

\author{
Gary L. Willingham and Betty Jean Gaffney*
}

ABSTRACT: The reactions of two spin-label cross-linking reagents with components of red blood cells have been studied. A bifunctional bis $(N$-hydroxysuccinimide ester) reagent passes readily through the membrane of intact red cells and reacts almost exclusively with hemoglobin. The rotational motion of hemoglobin inside of red cells may be studied by electron paramagnetic resonance (EPR) by using this spin-labeling method. A second cross-linking molecule, a negatively charged, disulfide-exchange reagent, reacts both with membrane components and with hemoglobin when intact red cells are labeled. Upon reaction with membranes stripped of components other than band 3 , this reagent readily produces dimers and higher oligomers of this protein. The EPR spectrum of band 3 labeled in this way shows that most of the spin-label molecules are highly immobilized on the protein. When the same reagent reacts with intact red cells, the cross-linked membrane products include components identified as band 3 dimers and a high molecular weight product consisting primarily of bands 1 and 2 but also containing lesser amounts of most of the other red cell membrane components and a slight amount of band 3 . The reagent was made radioactive to demonstrate that the spin-label disulfide exchange reagent is indeed involved in formation of cross-linked products. Comparison of Coomassie Blue staining and radioactivity in the region where band 3 dimers are expected on a one-dimensional sodium dodecyl sulfate-polyacrylamide gel shows that there is approximately 0.5 cross-linking reagent per protein

\footnotetext{
T he reactions of chemical reagents with components of the red blood cell have been used in studies of the geometry of erythrocyte membrane proteins, of the mobility of the band 3 protein in membranes, and of potential antisickling agents. Questions pertaining to the geometry of erythrocyte membranes have been addressed by using cross-linking reagents,

${ }^{\dagger}$ From the Department of Chemistry, The Johns Hopkins University, Baltimore, Maryland 21218. Received September 7, 1982. This work was supported by a grant from the National Institutes of Health (GM 28070). B.J.G. was a recipient of a Research Career Development Award (CA 000168) during part of the time the work was done.
}

in the region of band 3 dimers. Further proof that the spinlabel reagent actually is involved in cross-linking some of the band 3 dimers is complicated by the possibilities of sulfhydryl oxidation and disulfide rearrangement. Chymotrypsin cleavage at the external, red cell face results in no significant crosslinked fragments on two-dimensional gels. However, chymotrypsin cleavage of red cell ghosts does reveal two peptides off the diagonal of a two-dimensional gel. The approximate molecular weights of these peptides are 13000 and 8000 . There are two possible explanations of the results of the chymotrypsin treatments. The more likely is that the $13000-$ and 8000-dalton bands arise from an intramolecular cross-link or disulfide bond. The other explanation is that they do arise from an intermolecular cross-link, but this link is unstable during the chymotrypsin treatment of intact erythrocytes even though it is stable when cross-linked ghosts are treated with the protease. The 13000 - and 8000 -dalton fragments may arise from disulfide formation rather than from cross-linking by the spin-label reagent because they are also observed when intact red cells are treated with the monofunctional reagents 5,5'-dithiobis(2-nitrobenzoic acid) (DTNB) and [(2-aminoethyl)dithio]-2-nitrobenzoic acid. The results are consistent with a new disulfide bond being formed between an $\sim 21000$-dalton, transmembrane portion of band 3 and a small fragment of the 35000 -dalton segment released by internal chymotrypsin cleavage of ghosts.

in particular ones that can be cleaved for positive identification of the components of the cross-linked products (Wang \& Richards, 1974), by application of reagents to which the membrane is impermeable (Staros et al., 1975, 1981) and by chemical modification of specific proteolysis products (Steck, 1978; Rao \& Reithmeier, 1979; Ramjeesingh et al., 1980). It has been possible to use optical techniques to study the lateral mobility of band 3 in intact erythrocytes (Fowler \& Branton, 1977; Koppel \& Sheetz, 1981) and the rotational motion of this integral membrane protein in ghosts (Nigg \& Cherry, 1979) because several fluorescein and eosin derivatives are highly specific for band 3 among the protein components 
of the intact erythrocyte, with more than two-thirds of the fluorescent probes being found attached to this protein. Some agents tested for use in sickle-cell therapy pass through the red cell membrane and react with hemoglobins $S$ so that its properties are modified (Rosa et al., 1979). Antisickling agents should be uncharged or have groups that have an uncharged form such as carboxyl to pass through the membrane readily. As a generality, a series of increasingly hydrophobic molecules will have a maximum in the rate at which they pass through the membrane and react with components in the cytoplasm as a function of how hydrophobic they are (Defrise-Quertain et al., 1980). The rate for the least hydrophobic molecules will be limited by their low concentration in the membrane and for the most hydrophobic by their limited solubility in the aqueous cytoplasm.

We are interested in the extent to which the interaction of chemical reagents with membranes can be used to direct them to specific components of intact cells. In the previous paper (Gaffney et al., 1983) we have reported the partition coefficients between membrane and water and the probable orientation in a membrane for a number of hydrophobic, bifunctional spin-labels, including the cross-linking reagents I and II. Reagent $I$ is about 10 times more soluble in membranes
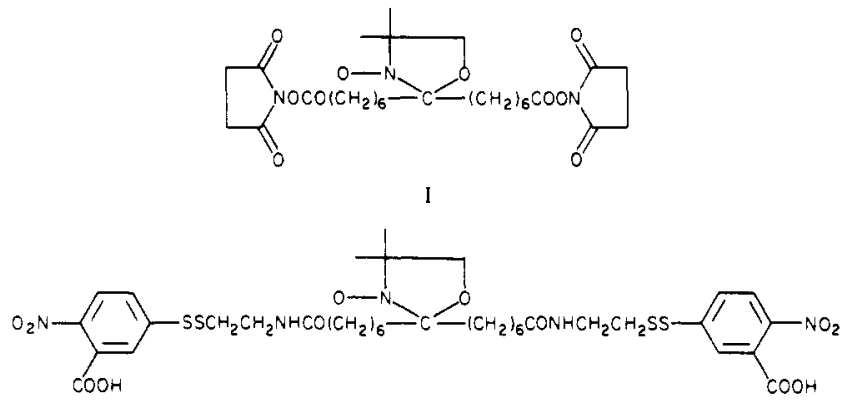

II

than II at neutral pH. Reagent II is partially negatively charged (carboxyl) and therefore expected to have some affinity for the band 3 anion channel. Reagent II is a mixed aryl-alkyl disulfide which should be unstable with respect to an alkyl-alkyl disulfide and can therefore be used to cross-link protein sulfhydryls. The resulting disulfide cross-links can be cleaved to facilitate analysis of products. A similar monofunctional, spin-label aryl-alkyl disulfide has recently been reported (Berliner et al., 1982). This report describes a survey of the reactions of I and II with human erythrocyte components.

\section{Materials and Methods}

Materials. Human blood was obtained from the Baltimore American Red Cross and was used within 1 week of the time it was drawn. Phosphate/saline is slightly higher in phosphate buffer than normal PBS; it is $20 \mathrm{mM}$ sodium phosphate and $150 \mathrm{mM}$ sodium chloride. $\alpha$-Chymotrypsin was obtained from Nutritional Biochemicals.

Synthesis of Radioactive Reagents. (1) 3-Oxy-4,4-dimethyloxazolidine Derivative of Bis [3-( $(N, N$ '-succinimidyloxy) carbony $l\left[\left[U-{ }^{14} C\right]\right.$ propy $\left.l\right]-8$-oxo-1,15-pentadecanediamide (IIn). 4-Aminobutyric acid (160 mg, $1.55 \times 10^{-3} \mathrm{~mol}$; Aldrich) was mixed with radioactive 4 -amino $\left[\mathrm{U}-{ }^{14} \mathrm{C}\right]$ butyric acid $(224$ $\mathrm{mCi} / \mathrm{mmol}$; Amersham) to a specific activity of approximately $30 \pm 5 \mu \mathrm{Ci} / \mathrm{mmol}$. It was allowed to react with $3-0 x y-2,2-$ bis[6-( $N$-succinimidyloxy $)$ carbonyl $)$ hexanyl] $-4,4-$ dimethyloxazolidine $\left(17.6 \mathrm{mg}, 3.11 \times 10^{-5} \mathrm{~mol}\right)$ in acetone as described earlier for similar reactions (Gaffney et al., 1983). The crude product was analyzed by $\mathrm{TLC}^{1}$ (chloroform-methanol-acetic acid, 90:10:0.1 v/v/v) but was used in the next reaction step without further purification. The radioactive reaction product was added to $7.9 \mathrm{mg}$ of $N$-hydroxysuccinimide (Aldrich; recrystallized from ethanol) and $13.1 \mathrm{mg}$ of 1-ethyl-3-[3-(dimethylamino)propyl]carbodiimide hydrochloride (EDAC; Bio-Rad). After $15 \mathrm{~h}$ at room temperature, the chloroform solution was washed 3 times with a saturated salt solution, dried, and evaporated. Subsequent chromatography was on $1.5 \mathrm{~g}$ of silica gel (ICN; $100-200$ mesh) with chloroformmethanol (98:2) as solvent. Thirty-drop fractions were collected, and fractions containing the major radioactive band were pooled to give $19.5 \mathrm{mg}$ of III. The radioactivity of this product was determined by counting $0.20 \mathrm{mg}$ and was found to be $3 \times 10^{4} \mathrm{cpm} / \mathrm{mg}$ (specific activity $11 \mu \mathrm{Ci} / \mathrm{mmol}$ based on one radioactive 4-aminobutyric acid group per bifunctional molecule). TLC (chloroform-methanol, 95:5; $R_{f} 0.45$ ) showed only one radioactive band.

(2) 3-Oxy-2,2-bis $\left[\left(\left(\left(2-\left((3-c a r b o x y-4-n i t r o p h e n y l)\left[{ }^{35} S\right] d i-\right.\right.\right.\right.\right.$ thio)ethyl)amino)carbonyl)hexanyl]-4,4-dimethyloxazolidine. Cysteamine ( $12 \mathrm{mg}, 1 \times 10^{-4} \mathrm{~mol}$; Aldrich) was mixed with $\left[{ }^{35} \mathrm{~S}\right]$ cysteamine $\left(2.5 \mathrm{mg}, 0.21 \times 10^{-4} \mathrm{~mol}, 11.8 \mathrm{mCi} / \mathrm{mmol}\right.$ when new, used when approximately $3 \mathrm{mCi} / \mathrm{mmol}$ remained; Amersham). It was allowed to react with 5,5'-dithiobis(2nitrobenzoic acid) as described in the previous paper (Gaffney et al., 1983). Some of this product ( $3 \mathrm{mg}, 1.1 \times 10^{-5} \mathrm{~mol}$ ) in $2 \mathrm{~mL}$ of $0.1 \mathrm{M}$ sodium phosphate, $\mathrm{pH} 7.5$, was allowed to react with 3-oxy-2,2-bis[6-(( $N$-succinimidyloxy $)$ carbonyl)hexanyl]-4,4-dimethyloxazolidine $\left(1 \mathrm{mg}, 1.77 \times 10^{-6} \mathrm{~mol}\right)$ in $50 \mu \mathrm{L}$ of dimethylformamide under conditions described in the previous report. In this case, the product was purified on LH20 Sephadex $(1.75 \times 22 \mathrm{~cm}$ column $)$ with methanol as solvent. The radioactive fractions were pooled to give $0.4 \mathrm{mg}$ of product [based on $A_{323}$ and an extinction coefficient $\epsilon_{323}$ of $5 \times 10^{-3} \mathrm{M}^{-1} \mathrm{~cm}^{-1}$ (methanol)] $\left(4.2 \times 10^{-7} \mathrm{~mol}, 24 \%\right.$ yield) which moved as a single spot on TLC (chloroform-methanol-acetic acid, 80:20:0.1; $R_{f} 0.51$ ). The activity of the product was $2.2 \times 10^{6} \mathrm{cpm} / \mathrm{mg}$.

Cross-Linking of Hemoglobin. Washed red blood cells were lysed with 5 volumes of $5 \mathrm{mM}$ phosphate, $\mathrm{pH} 8.0$, for $10 \mathrm{~min}$ at $0^{\circ} \mathrm{C}$ and centrifuged at $19000 \mathrm{~g}$ for $15 \mathrm{~min}, 4^{\circ} \mathrm{C}$. The supernatant was transferred to a new tube and centrifuged at $15000 \mathrm{rpm}$ for $30 \mathrm{~min}$. The second supernatant was passed through a Miracloth (Chicopee Mills) filter and concentrated in a collodion bag (70000-dalton cutoff, Schleicher \& Schuell) to $0.21 \mathrm{mM}$ (tetramer) in phosphate/saline, $\mathrm{pH} 6.0$, for labeling. The isolated hemoglobin was cross-linked by evaporating measured amounts of 3-oxy-2,2-bis[6-( $(N$-succinimidyloxy)carbonyl)hexanyl]-4,4-dimethyloxazolidine in several test tubes and adding $0.21 \mathrm{mM}$ hemoglobin in amounts such that the final concentration of bifunctional spin-label was $0.2-20 \mathrm{mM}$. Cross-linking was carried out for $12 \mathrm{~h}$ at $22^{\circ} \mathrm{C}$.

When hemoglobin in intact red blood cells was labeled with the bis $(N$-hydroxysuccinimide ester) spin-label, $50 \mu \mathrm{L}$ of washed red cells was mixed with $50 \mu \mathrm{L}$ of phosphate-buffered saline at $\mathrm{pH} 6$, and $1.2 \mathrm{mg}(1.06 \mu \mathrm{mol})$ of label I was added in four 0.3-mg aliquots. Each aliquot was incubated for $4 \mathrm{~h}$ at $22{ }^{\circ} \mathrm{C}$ and washed 3 times in buffer, and another aliquot was added. The reaction was quenched by washing cells 3 times in buffer containing $50 \mathrm{mM}$ glycine; cells were lysed, and hemoglobin was isolated and concentrated as above to 8.5 $\times 10^{-4} \mathrm{M}$ (tetramers) for EPR spectroscopy.

\footnotetext{
1 Abbreviations: EPR, electron paramagnetic resonance; NEM, $N$ ethylmaleimide; TLC, thin-layer chromatography; $C B$, Coomassie Blue; DTT, dithiothreitol; $\mathrm{NaDodSO}_{4}$, sodium dodecyl sulfate; DTNB, 5,5'dithiobis(2-nitrobenzoic acid); DML, dimyristoyllecithin.
} 
Measurement of the Kinetics of Hydrolysis of I by EPR. Liposome suspensions containing $10^{-2} \mathrm{M} \mathrm{DML}$ and $2.5 \times 10^{-4}$ $\mathrm{M}$ bis $(N$-hydroxysuccinimide ester) label I were made in 0.1 $\mathrm{M}$ sodium phosphate for $\mathrm{pHs}$ from 6 to 8 , in $0.1 \mathrm{M}$ sodium borate for pHs 9-10, and in a 1:1 mixture of the two buffers for $\mathrm{pH}$ 8.5. The rate of hydrolysis product formation was followed by EPR measurements at $22^{\circ} \mathrm{C}$ begun immediately after the lipid was suspended in buffer.

Cross-Linking of Band 3. Band 3 was labeled in two states: as virtually the sole protein in protein-depleted red cell membranes and in intact red cells.

Protein-depleted membranes were prepared by the method of Wolosin et al. (1977) with the following modifications. All washes after preparation of ghosts were performed twice, and DTT was omitted from the buffers. The final membrane preparation was $2 \mathrm{mg} / \mathrm{mL}$ in protein and showed traces of spectrin bands 1 and 2 as the only proteins other than band 3. The membranes $(800 \mu \mathrm{L})$ were mixed with $800 \mu \mathrm{L}$ of phosphate/saline at $\mathrm{pH} 8.0$ and $1.8 \mathrm{mg}$ in $10 \mu \mathrm{L}$ of dimethylformamide of the mixed disulfide reagent 3-oxy-2,2bis [(( (2-((3-carboxy-4-nitrophenyl) dithio)ethyl)amino $)$ carbonyl)pentanyl]-4,4-dimethyloxazolidine, II, and the mixture was incubated at $37^{\circ} \mathrm{C}$ for $1 \mathrm{~h}$. The sample was washed 3 times in phosphate/saline, $\mathrm{pH} 8.0$, and was centrifuged at $12000 \mathrm{~g}$ for $10 \mathrm{~min}$ at $20^{\circ} \mathrm{C}$. The pellet was resuspended in buffer and treated with $2 \mathrm{mM} N$-ethylmaleimide for $1 \mathrm{~h}$ at $37^{\circ} \mathrm{C}$, washed as above 3 more times, and dialyzed overnight at room temperature against two $500-\mathrm{mL}$ quantities of phosphate/saline, $\mathrm{pH} 8.0$, plus $1 \mathrm{mM}$ phenylmethanesulfonyl fluoride.

The buffer for reaction of II with intact red cells contained $150 \mathrm{mM}$ sodium chloride, $8 \mathrm{mM}$ potassium chloride, $2 \mathrm{mM}$ magnesium sulfate, $10 \mathrm{mM}$ sodium phosphate, and $10 \mathrm{mM}$ glucose at pH 7.8. Packed red cells were warmed for $30 \mathrm{~min}$ at $37^{\circ} \mathrm{C}$ and washed 3 times with this buffer prior to labeling. Label II ( $0.2 \mathrm{mg}$ in $2 \mu \mathrm{L}$ of dimethylformamide) was added to $200 \mu \mathrm{L}$ of packed cells and $200 \mu \mathrm{L}$ of the above buffer, and the mixture was incubated at $37^{\circ} \mathrm{C}$ for $1 \mathrm{~h}$. Labeled cells were lysed and washed 3 times with $5 \mathrm{mM}$ phosphate, $\mathrm{pH} 8.0$, plus $10 \mathrm{mM} N$-ethylmaleimide. A 4-fold increase in label/cell ratio did not increase the yield of band 3 dimers apparent on two-dimensional gels. A 10-fold decrease resulted in almost no dimer formation. When radioactive II was used, the reaction components were $0.4 \mathrm{mg}$ of II, $100 \mu \mathrm{L}$ of packed cells, and $100 \mu \mathrm{L}$ of buffer.

Procedures for Chymotrypsin Treatment of Membranes. Packed, intact red cells (200-400 $\mu \mathrm{L})$ and ghosts were treated with $\alpha$-chymotrypsin according to the procedure of Steck et al. (1976). Spin-labeled, intact cells were treated with $2 \mathrm{mM}$ $\mathrm{N}$-ethylmaleimide for $1 \mathrm{~h}$ at $37^{\circ} \mathrm{C}$ after labeling to prevent disulfide exchange at later steps in the experiment. Intact cells ( $400 \mu \mathrm{L}, 50 \%$ hematocrit) were treated overnight at room temperature with $160 \mu \mathrm{g}$ of $\alpha$-chymotrypsin. Ghosts (1-1.5 $\mathrm{mg} / \mathrm{mL}$ ) were treated for $1 \mathrm{~h}$ with $800 \mu \mathrm{g} / \mathrm{mL}$ of the protease at room temperature. In each case, $2 \mathrm{mM}$ phenylmethanesulfonyl fluoride was added for $10 \mathrm{~min}$ at room temperature to quench the reaction. Peripheral proteins were removed with ice-cold $10 \%$ acetic acid and the membranes pelleted $(19000 \mathrm{~g}$, $30 \mathrm{~min}, 0^{\circ} \mathrm{C}$ ). Pellets were resuspended, brought to $\mathrm{pH} 7$, pelleted, and solubilized for gels.

Two steps were taken to stabilize the cross-linked products in samples treated with $\alpha$-chymotrypsin. First, after intact red cells were labeled and treated with the protease, the cells were exposed to $2 \mathrm{mM} \mathrm{NEM}$ for $1 \mathrm{~h}$ at $22^{\circ} \mathrm{C}$ to prevent disulfide exchange in the following steps. Intact red cell samples which were to be proteolyzed as ghosts were treated with NEM before lysis to ensure optimal protection of cysteines (Rao, 1979). The second stabilization step taken was to bring membranes which had been stripped of peripheral proteins in $10 \%$ acetic acid back to $\mathrm{pH} 7.0$ by suspending the pelleted membranes in $5 \mathrm{mM}$ phosphate buffer and adjusting the $\mathrm{pH}$ with dilute sodium hydroxide. Neither of these procedures significantly altered the results of two-dimensional gel analysis.

$\mathrm{NaDodSO}_{4}-$ Polyacrylamide Gels. Agarose (Bio-Rad) used as a reducing band at the top of two-dimensional gels was purified to remove a Coomassie Blue staining impurity by treating $10 \mathrm{~g}$ of agarose for $3 \mathrm{~h}$ in $500 \mathrm{~mL}$ of $1 \%$ sodium dodecyl sulfate at $22^{\circ} \mathrm{C}$, collecting it on a glass-sintered funnel, washing it with water and then $200 \mathrm{~mL}$ of methanol, and allowing it to dry overnight at room temperature and 1 torr of pressure.

Gels for cross-linked hemoglobin samples were run according to Fairbanks et al. (1971) and contained 9\% acrylamide. One-dimensional gels for cross-linked red cell ghosts and controls contained 3.2\% acrylamide (Fairbanks et al., 1971). The procedure of Wang \& Richards (1974) was used for two-dimensional gels of red cell ghosts. The gel for the first dimension was run as above; the second dimension consisted of a $5.2 \%$ acrylamide slab. For two-dimensional gel analysis of chymotrypsin treatment of intact cells, both dimensions were of $5.2 \%$ acrylamide. Chymotrypsin treatment of ghosts was analyzed on a gel of $5.2 \%$ and $9 \%$ acrylamide in the first and second dimensions, respectively.

\section{Results}

Reactions of Cross-Linking Reagents with Isolated Hemoglobin and Band 3. In preliminary studies of reactions of I and II with components of intact red blood cells, we observed that hemoglobin was virtually the only target of I and that II, while reacting to a considerable extent with hemoglobin, also produced cross-linking of the membrane components spectrin and band 3 . We therefore carried out preliminary experiments on cross-linking by $I$ of isolated hemoglobin and cross-linking by II of band 3 in membranes from which other proteins had been removed.

On the basis of mobility $\mathrm{NaDodSO}_{4}$-polyacrylamide gel electrophoresis on the products of reaction of I with isolated hemoglobin are consistent with a statistical cross-linking pattern. At pH 6.0 globin dimers begin to be apparent on gels when the reaction time is $12 \mathrm{~h}$ at $22^{\circ} \mathrm{C}$ and the label concentration exceeds about $1 \mathrm{~mol}$ of label/hemoglobin tetramer. Increasing formation of higher oligomers (trimers, tetramers, and higher molecular weight polymers) is observed up to a ratio of $100 \mathrm{~mol}$ of label/hemoglobin tetramer. Clearly at this high label/protein ratio and reaction time, the reactive amino groups on hemoglobin are not saturated with labels which have bound at one end only. At $\mathrm{pH} 6.0$, the competing hydrolysis reaction is insignificant.

Red cell membranes that had been stripped of all peripheral proteins and treated with Triton $\mathrm{X}-100$ to remove glycophorin (Wolosin et al., 1977) were allowed to react with the crosslinking reagent to study the reaction of II exclusively with band 3. Figure $1 \mathrm{~b}$ shows an acrylamide gel electrophoresis pattern of the products of this reaction. Monomers, dimers, and tetramers of band 3 , in increasing amounts, are evident. If both ends of reagent II are attached to the protein, an EPR spectrum characteristic of a strongly immobilized label is expected. Alternatively, if only one end is attached, it is reasonable to expect a spectrum showing considerable mobility, much as is observed when monofunctional reagents derived 


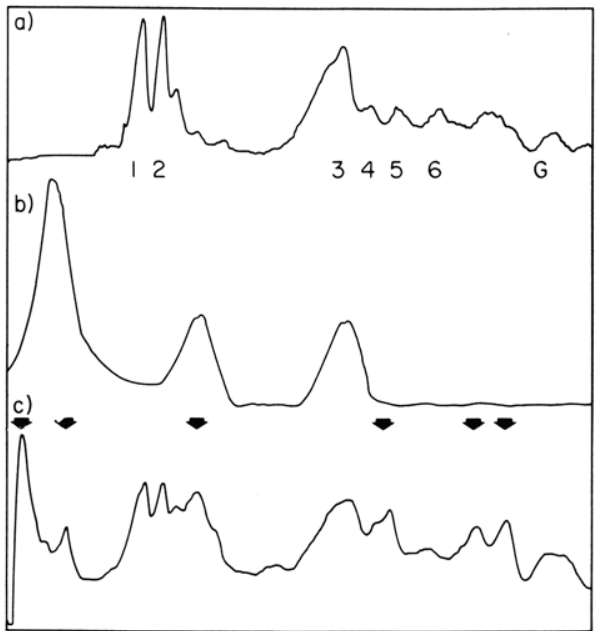

FIGURE 1: Densitometer scans are shown of Coomassie Blue stained one-dimensional $\mathrm{NaDodSO}_{4}$ - polyacrylamide gels of (a) normal ghosts, (b) protein-depleted band 3 membranes cross-linked with label II, and (c) intact erythrocytes cross-linked with label II and run as hemoglobin-free ghosts. Gels were run according to Fairbanks et al (1971) without reducing agents and contained $0.1 \% \mathrm{NaDodSO}_{4}$ and $3.2 \%$ acrylamide. Protein bands in gel a are numbered according to Fairbanks et al., and cross-linked products in gel $\mathrm{c}$ are indicated by arrows.

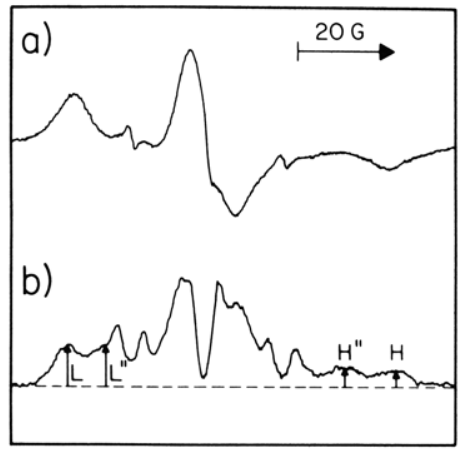

FIGURE 2: Electron spin resonance spectra of purified band 3 labeled with reagent II are in (a), first-harmonic, in-phase absorption spectrum $\left(V_{1}\right)$, and in (b), second-harmonic, $90^{\circ}$ out-of-phase absorption spectrum $\left(V_{2}^{\prime}\right)$. Modulation amplitudes were 1.25 and $5 \mathrm{G}$, and microwave powers were 20 and $63 \mathrm{~mW}$ for (a) and (b), respectively. The positions of $L, L^{\prime \prime}, H$, and $H^{\prime \prime}$ are indicated in spectrum $b$ and are measured from the base line indicated by the dashed line.

from the spin-label fatty acids (Davoust et al., 1979) are used to label membrane proteins. For II, the distance between the spin-labeled atom and the site of attachment to the protein is 11 atoms. Figure 2 shows both the conventional and the saturation transfer EPR spectra resulting from labeling band 3 membrane samples with II. The dominant contribution to the spectrum is a broad component indicative of highly immobilized label. A smaller component of more mobile label is also seen. Spectral parameters from the saturation transfer spectrum (Thomas et al., 1976) suggest a correlation time for labeled band 3 of $>10^{-5} \mathrm{~s}$, although the possibility of anisotropic motion and the uncertain state of aggregation of the protein make this number a very crude approximation. Although a variety of experimental conditions for allowing II to react with band 3 in intact red blood cells was tried, none of these gave sufficiently exclusive labeling of band 3 , relative to hemoglobin and other cell components, that the motion of band 3 in intact erythrocytes could be studied by EPR.

Rotational Motion of Hemoglobin Inside Red Blood Cells $\mathrm{Can}$ Be Detected with I. Two reasons for including a spin-label group in cross-linking reagents are that the course of the reaction can be examined by EPR, and if the reaction is

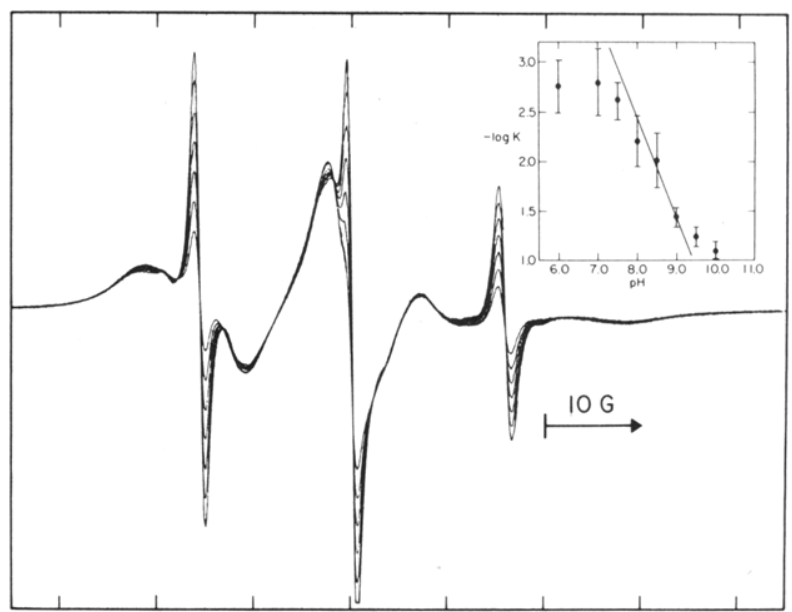

FIGURE 3: Multiple scans at progressive time intervals of the EPR spectrum of label $I$ in a $1 \%$ DML liposome suspension are shown. The increasing sharp signal is due to hydrolysis of the membrane soluble di-NHS ester to the water-soluble diacid. The high field free signal from which data to calculate the hydrolysis rate constant, $k$, were obtained is denoted with an arrow. A plot of $-\log k$ vs. $\mathrm{pH}$ is shown in the inset. A line with the predicted slope of 1 is drawn through the data taken at $\mathrm{pH} 8.0,8.5$, and 9.0.

specific for a single component of a cell, the rotational motion and/or conformational changes of this component can be studied in the intact cell. Both reagents I and II react with hemoglobin when intact red cells are labeled, but $I$ is more specific. In spite of the numerous amino groups on membrane lipids and proteins, no EPR signal is observed for membranes prepared after intact cells are labeled with I. To extent this observation, a bis $(N$-hydroxysuccinimide ester) reagent similar to I, but extended by radioactive 3-aminobutyric acid groups (to give III) was allowed to react with intact cells. Again, at

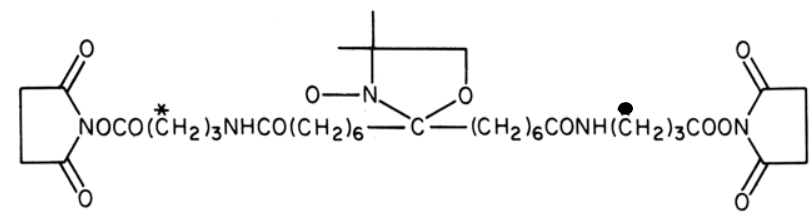

III

least $99 \%$ of the radioactivity was found in the cytoplasm, and the only labeled product detected on gels was hemoglobin.

Hydrolysis of $N$-hydroxysuccinimide esters competes with reaction of reagent I with amino groups. The rate of hydrolysis can be determined conveniently by EPR with a sample which contains membranes. The reason that the presence of membranes makes this possible is that the $N$-hydroxysuccinimide ester $\mathrm{I}$ is about 20 times more soluble in membranes than is its hydrolysis product (Gaffney et al., 1983) and the EPR spectra in membrane and in water are very different. For example, Figure 3 shows a set of spectra recorded as a function of time. The increase in the sharp, three-line component of the spectrum results from the hydrolysis of I with time and indicates that the amount of paramagnetic material dissolved in water increases with time. The label $\left(2.5 \times 10^{-5} \mathrm{M}\right)$ is in excess over hydroxide ion concentration below $\mathrm{pH} 9$, so the reaction should be first order in hydroxide in this range. Inset of Figure 3 shows that this is approximately so for $\mathrm{pH}$ 8-9. The apparently lower rate below pH 8 is certainly an artifact resulting from the fact that the partition coefficient of the hydrolysis product increases (in favor of membrane) at lower $\mathrm{pH}$ as less of this diacid is ionized. By use of the slope for a first-order reaction (as drawn in Figure 3, inset), the halftime for hydrolysis of $\mathrm{I}$ is $30.7 \mathrm{~h}$ at $\mathrm{pH} 7.0$ and $115.5 \mathrm{~h}$ at $\mathrm{pH}$ 


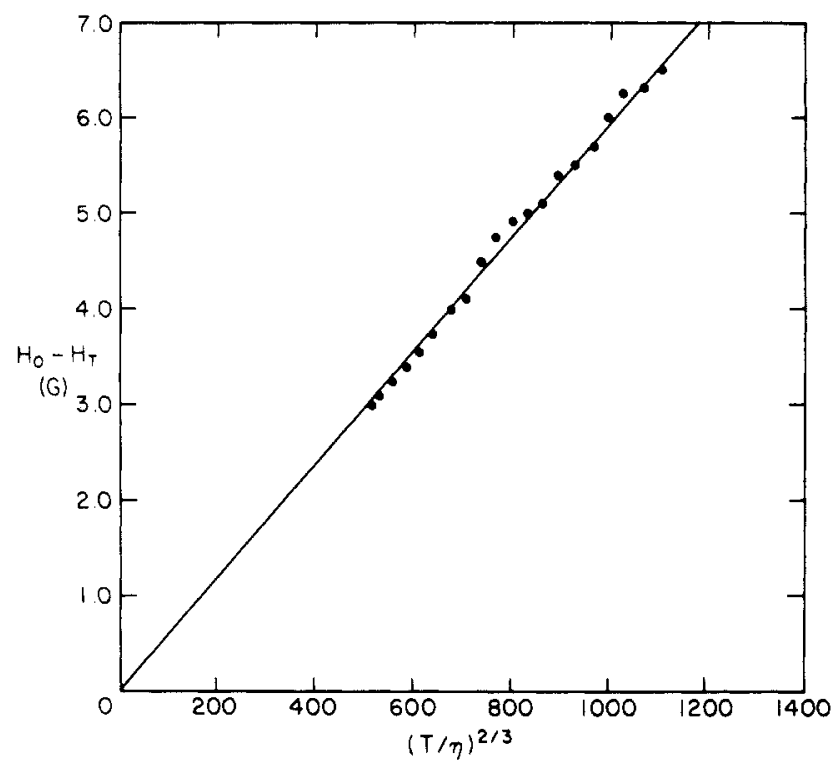

FIGURE 4: Magnetic field positions of extrema in the EPR spectra of hemoglobin $(5.6 \mathrm{~g} / 100 \mathrm{~mL}$ in buffer, $\mathrm{pH} 6.0)$, labeled with reagent I while in intact erythrocytes and then isolated, are plotted. $H_{\mathrm{T}}$ and $H_{0}$ are the positions (in G) of the high field minima of the spectra of hemoglobin at temperatures, $T$, and of that of immobilized hemoglobin (frozen solution at $-40^{\circ} \mathrm{C}$ ), respectively. $(T / \eta)^{2 / 3}$ is in units of $(\mathrm{K} / \mathrm{P})^{2 / 3}$

6.0. Thus, for minimization of hydrolysis of I during crosslinking of whole cells, the reaction was carried out at $\mathrm{pH} 6.0$.

Hemoglobin which had been labeled by reaction of I with intact erythrocytes and then isolated showed an EPR spectrum typical of a label immobilized on a macromolecule. By $\mathrm{Na}$ $\mathrm{DodSO}_{4}$-polyacrylamide gel electrophoresis $25 \%$ of the globin had been cross-linked to yield dimers, and no higher oligomers were apparent. The EPR spectra of hemoglobin spin-labeled inside intact red cells, and then isolated, were compared in the temperature range from 0 to $37^{\circ} \mathrm{C}$ with the spectra of labeled hemoglobin still inside red cells. As temperature increased, the outer extrema of the spectra moved inward in both cases although the separation of the outer extrema was always greater for hemoglobin inside the red cell (undoubtedly due to the increased viscosity of a $33 \%$ protein solution over that of a $5.6 \%$ solution). Figure 4 shows a plot of the shift, $H_{0}$ $H_{\mathrm{T}}$, of the high-field EPR peak as a function of $(T / \eta)^{2 / 3}$ for an isolated hemoglobin sample (Shimshick \& McConnell, 1972). The data for hemoglobin inside the red cells are shifted from that of the isolated protein by an amount equivalent to an increase in viscosity of $1.9\left(\right.$ at $0^{\circ} \mathrm{C}$ ) and 1.4 (at $37^{\circ} \mathrm{C}$ ).

Reactions of II with Band 3. With radioactive sulfur incorporated in reagent II, a low level of radioactivity could be detected on a gel at a level of less than one cross-link per protein pair. Figure 5 shows a one-dimensional gel for membranes isolated after reaction of radioactive II with intact red cells. Apparent radioactive bands occur at the positions of hemoglobin and its higher oligomers, in band 3 , in the region between band 3 and spectrin and in a high molecular weight product at the top of the gel. Were there one label per protein, the counts would decrease logarithmically on the gel from right to left. Table I lists the estimates of the relative number of labels per protein in various regions of the gel shown in Figure 5 . In the region where band 3 dimers are expected (fractions $11-14$ ), there is about 0.5 label per protein, based on comparison of radioactivity and Coomassie Blue staining.

Figure 6A shows a two-dimensional gel of a sample prepared in the same way as that in Figure 5. Approximately 50\% of band 3 appears as dimers. This result was achieved by al-

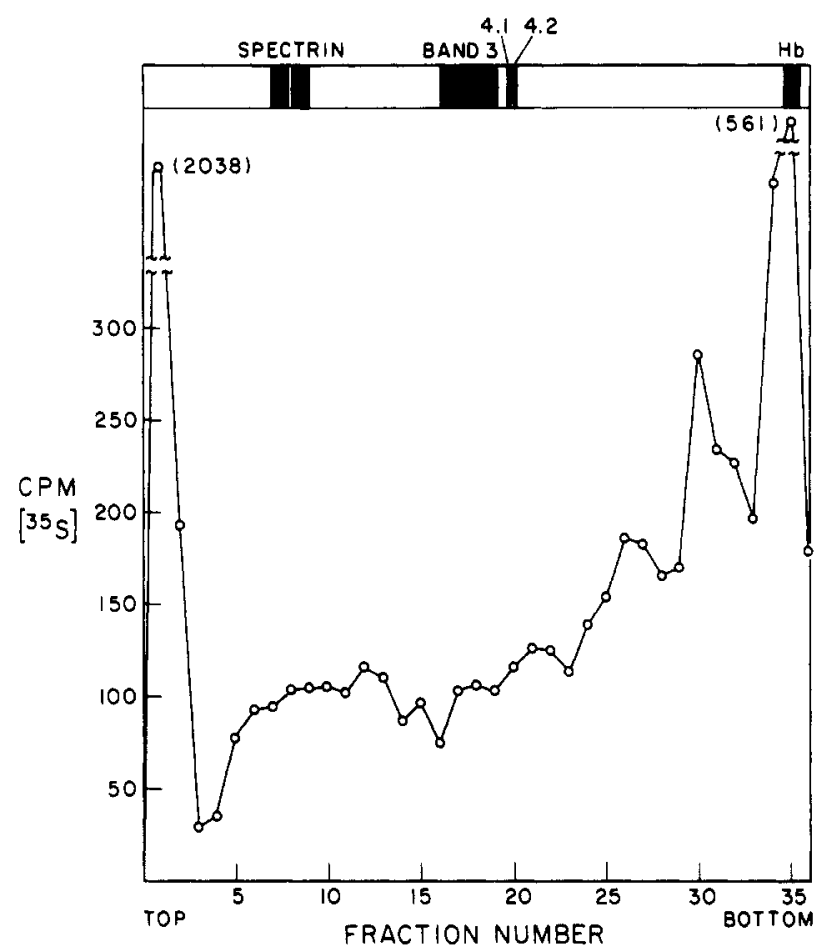

FIGURE 5: Intact erythrocytes were labeled with ${ }^{35} \mathrm{~S}$ label II, lysed to remove hemoglobin, and run on a $3.2 \% \mathrm{NaDodSO}_{4}$-polyacrylamide electrophoretic gel. After electrophoresis, the gel was cut into $3-\mathrm{mm}$ slices, and the slices were digested in hydrogen peroxide and counted. $\mathrm{cpm}$ of ${ }^{35} \mathrm{~S}$ is plotted vs. gel fraction numbers. The drawing of the gel at the top of the figure indicates the approximate positions of various bands in un-cross-linked ghosts.

Table I: Molar Ratios of Radioactivity ${ }^{a}$ to Protein for Membranes from Cells Labeled with II

\begin{tabular}{ccccc}
\hline gel fractions & $\begin{array}{c}\mathrm{CB}^{b} \\
\text { stain }\end{array}$ & ${ }^{*} \mathrm{cpm}\left({ }^{35} \mathrm{~S}\right)^{c}$ & $\begin{array}{c}M_{\mathrm{r}} \\
\text { (approx) }^{d}\end{array}$ & $\begin{array}{c}\text { rel mol of } \\
{ }^{35} \mathrm{~S} / \mathrm{mol} \text { of } \\
\text { protein }\end{array}$ \\
\hline $1-2$ & 1.15 & 2190 & $>540 \mathrm{~K}$ & 18 \\
$6-10$ & 1.09 & 401 & $240 \mathrm{~K}$ & 1.6 \\
$11-14$ & 1 & 339 & $168 \mathrm{~K}$ & 1.0 \\
$17-19$ & 1.20 & 247 & $91 \mathrm{~K}$ & 0.3 \\
$20-23$ & 0.73 & 398 & $65 \mathrm{~K}$ & 0.6 \\
$24-28$ & 0.36 & 732 & $41 \mathrm{~K}$ & 1.5 \\
$29-33$ & 0.73 & 1016 & $25 \mathrm{~K}$ & 0.6 \\
$34-36$ & 0.36 & 1061 & $16 \mathrm{~K}$ & 0.8
\end{tabular}

${ }^{a}$ Data shown in Figure 5. ${ }^{b} \mathrm{CB}$ refers to Coomassie Blue. The assumption is made that the amount of stain is proportional to the weight of protein. ${ }^{c}$ Data corrected for background counts. ${ }^{d}$ The approximate molecular weights were obtained by making a linear extrapolation of (ln molecular weight) between spectrin and globin monomer positions, using as molecular weights of band 1 and globin 240000 and 16500 , respectively.

lowing $0.6 \mathrm{mg}$ of II to react with $300 \mu \mathrm{L}$ of packed red blood cells and $300 \mu \mathrm{L}$ of buffer. When one-tenth this amount of label per cell was used, no cross-linked products were detected on two-dimensional gels. The gel in Figure 6A also shows dimers of the spectrin bands. The components of the high molecular weight band are noticeably diminished in band 3 but contain most of the other membrane bands. The results shown are reminiscent of those obtained by air oxidation of ghosts at $\mathrm{pH} 7.0$ and $37^{\circ} \mathrm{C}$, or at low pH and $0^{\circ} \mathrm{C}$ (Liu et al., 1977). However, in control experiments in which intact red cells were incubated with either no addition, an amount of dithionitrobenzoic acid (DTNB), or 5-[(2-aminoethyl)dithio]-2-nitrobenzoic acid equal to the number of moles of disulfide groups used in labeling by II, no bands off the diagonal were observed in gels of intact ghosts (see later dis- 

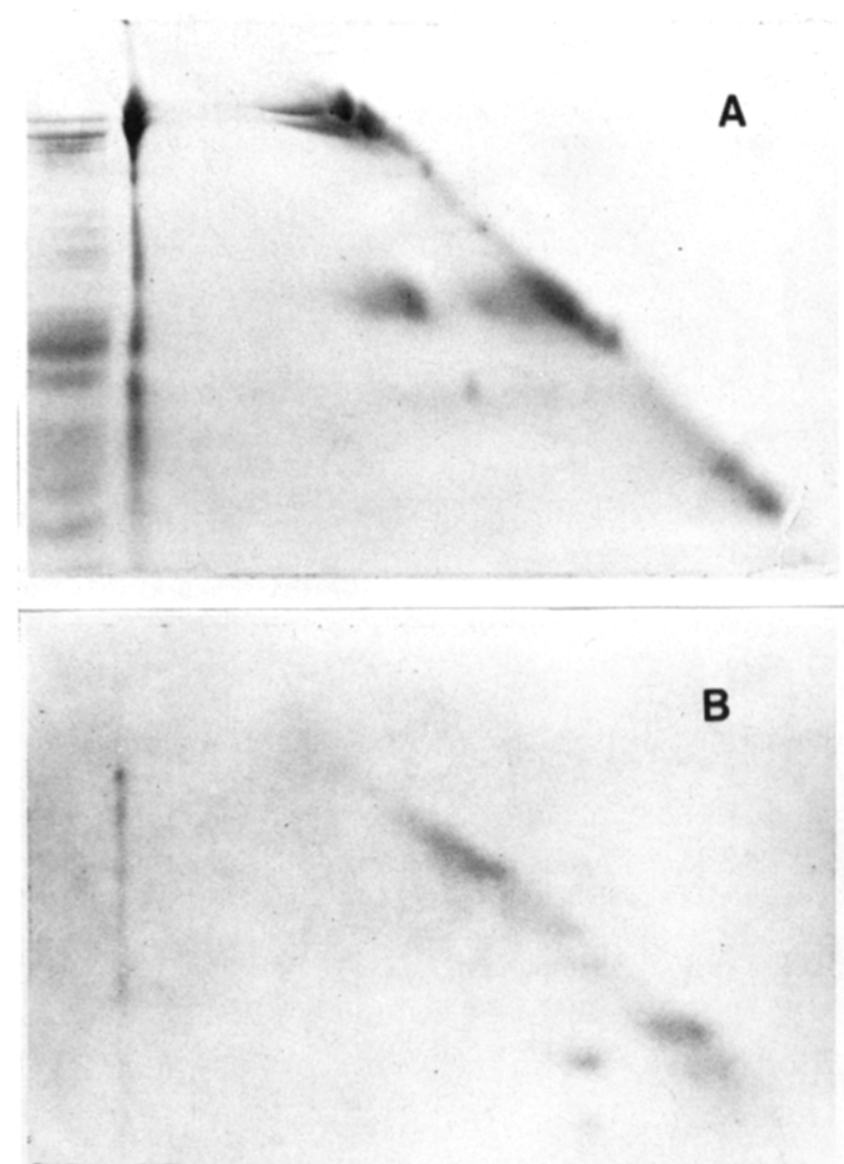

FIGURE 6: Two-dimensional $\mathrm{NaDodSO}_{4}$-polyacrylamide gels of (A) intact erythrocytes cross-linked with label II and run as ghosts and (B) a sample treated as in (A), followed by conversion to ghosts and treatment with $800 \mu \mathrm{g} / \mathrm{mL}$ chymotrypsin for $1 \mathrm{~h}$ at $22^{\circ} \mathrm{C}$, were run according to Wang \& Richards (1974). Electrophoresis was performed in (A) on $3.2 \%$ and in (B) on $5.6 \%$ acrylamide gels under nonreducing conditions in the first dimension. A slab gel with a $2.5-\mathrm{cm}$ agarose layer containing $10 \% \beta$-mercaptoethanol on top of a resolving gel of $5.6 \%$ (A) or $9 \%$ (B) acrylamide formed the second dimension. The gel in (A) was dried between cellulose sheets before photography and that in (B) was photographed wet.

cussion of DTNB effects, though). While it is still possible that the presence of II promotes disulfide formation or exchange in which it is not involved, it seems unlikely that all of the cross-linking of band 3 can be accounted for in this way based on the above controls and the data in Figures 5 and 6A.

The site of the band 3 cross-link was examined further by chymotrypsin cleavage (Steck et al., 1976; Rao \& Reithmeier, 1979). Although about $50 \%$ of band 3 appeared as a dimer on gels of membranes from intact cells reacted with II, but not subjected to proteolysis, (Figure 6A), chymotrypsin cleavage of the labeled, intact cells and acetic acid stripping (Steck et al., 1976) left only traces of cross-linked products on two-dimensional gels. This result indicates that the cross-links from II observed before proteolysis are probably not stable to the stripping conditions.

The possibility that the radioactivity found in the region of monomeric band 3 after reaction with II (Figure 5) included an intramolecular cross-link was investigated by further chymotrypsin cleavage of band 3 at the cytoplasmic side (Steck et al., 1976; Rao \& Reithmeier, 1979). As shown in Figure 6B, this second step of chymotrypsin cleavage now results in two spots off the diagonal (one very faint spot is in a vertical line below the clearly visible off-diagonal spot). The assignment of molecular weights to the bands in the gel of Figure 6B was made with reference to the Bio-Rad low molecular weight standards of $14400,21500,31000,45000,66200$, and 92500 (lysozyme, soybean trypsin inhibitor, carbonic anhydrase, ovalbumin, bovine serum albumin, and phosphorylase $b$ ). When the sample for Figure 6B was run on a one-dimensional gel, under nonreducing conditions, bands were apparent at approximately $14000,21000,30000$, and 38000 (diffuse) daltons with respect to the standards. A one-dimensional gel of the same sample under reducing conditions showed a loss of the 21000 -dalton band and the appearance of new bands at slightly less than 14000 and a fragment smaller than this. The diffuse 38000 -dalton band remained. The 30000-dalton band was less apparent on reduced gels. These data and those of the two-dimensional gel shown in Figure 6B suggest that the 21000 -dalton band has given rise to 13000 - and 8000 -dalton ones upon reduction (the weight of 8000 daltons is based simply on the difference of 21000 and 13000 daltons).

\section{Discussion}

A number of acylating and alkylating reagents react covalently with hemoglobin in intact erythrocytes. Many of these previous studies have been directed toward therapy for sickle-cell anemia (Rosa et al., 1979; Walder et al., 1980). Because reagent $I$ is paramagnetic, it also is possible to investigate the rotational motion of hemoglobin inside intact red blood cells using this reagent. We have done this for normal human red blood cells, but the reagent may also prove useful for studying certain red cell or hemoglobin pathologies. In our studies, EPR measurements were made only on hemoglobin which had been labeled in the intact erythrocyte. About one-quarter of the globin chains are cross-linked as dimers under the conditions of labeling, and no high molecular weight complexes were observed. Thus, the EPR spectra are expected to reflect rotational motion of the hemoglobin tetramer if the spin-label is immobilized on the protein. Hemoglobin labeled in cells and then isolated was examined at a concentration of $5.6 \mathrm{~g} / 100 \mathrm{~cm}^{3}$ (based on $\epsilon_{541 \mathrm{~nm}}=55200 \mathrm{M}^{-1} \mathrm{~cm}^{-1}$; Antonini \& Brunori, 1971). For this concentration of hemoglobin at $25^{\circ} \mathrm{C}$, the viscosity is estimated to be $1.334 \mathrm{cP}$ using the empirical relation (Kunitz et al., 1933)

$$
\frac{\eta_{\mathrm{s}}}{\eta_{\mathrm{w}}}=\frac{1+0.5 \phi}{(1-\phi)^{4}}
$$

where $\eta_{\mathrm{s}}=$ solution viscosity, $\eta_{\mathrm{w}}=$ water viscosity, and $\phi=$ solution volume fraction occupied by protein. At this viscosity and temperature, the rotational correlation time of hemoglobin, taking the radius of hemoglobin as $2.9 \mathrm{~nm}$ (Hyde \& Thomas, 1973), predicted from the Stokes-Einstein relation is $33 \mathrm{~ns}$. By use of calibration curves for the inward shift of EPR spectral extrema with increasing correlation times (McCalley et al., 1972; Freed, 1976), the spectral data suggest a faster motion, with a correlation time of $8-9$ ns. At $5^{\circ} \mathrm{C}$, the calculated and experimentally derived correlation times are 61 and $20 \mathrm{~ns}$, respectively. The EPR spectra clearly reflect components of motion in addition to overall rotation of the protein. However, the spectra of labeled hemoglobin inside red cells indicate longer correlation times than those of the more dilute, isolated hemoglobin at a given temperature. For instance, at $0^{\circ} \mathrm{C}$, the spectra of labeled hemoglobin inside red cells correspond to a correlation time of $40 \mathrm{~ns}$ and, at $37^{\circ} \mathrm{C}$, to $8 \mathrm{~ns}$. It seems reasonable to attribute this difference to the increased viscosity inside red cells due to increased protein concentration. We are not able with the present data to define further the additional component of motion that contributes to the EPR spectra. However, because the label does respond to changes in protein concentration, as well as to temperature, 
it is reasonable to expect that EPR studies with this derivative might be used to study aggregation of hemoglobins inside red cells (Hu \& Johnson, 1981), or association of hemoglobin with membranes (Fung, 1981).

The locations and reactivity of the sulfhydryl groups of band 3 have been examined in detail (Steck, 1978). There are three sulfhydryls available to radioactive $N$-ethylmaleimide (NEM) when ghosts are labeled, but five are reactive in intact erythrocytes (Rao \& Reithmeier, 1979). Chymotrypsin reaction at the external side of the membrane cleaves band 3 into two segments of 38000 and 55000 daltons. The smaller segment has two of the sulfhydryls and the larger, the other three. The 55000-dalton fragment may be cleaved further by chymotrypsin digestion of ghosts to give a 17000-19000dalton transmembrane subfragment and a water-soluble 36000-38000-dalton portion containing the three sulfhydryls reactive with NEM. The amino acid composition of the 17000-19000-dalton subfragment shows one additional sulfhydryl group (Ramjeesingh et al., 1980), which may be the site by which DTNB inhibits water flow through the red cell membrane (Brown et al., 1975).

Since virtually no cross-linked products were observed in our experiments after cleavage at the first, external chymotrypsin site, the products we have observed after the second cleavage could only result from an intramolecular link within the 55000-dalton portion. Our reagent II is a quite long cross-linking reagent and might be expected to produce cross-links not observed with other reagents. Alternatively, II could promote disulfide formation, without itself being involved either because it is reasonably hydrophobic and capable to catalyzing reaction of buried sulfhydryls or because it reacts with some other region of band 3 and produces a conformational change that facilitates new disulfide bond formation. We have tested these possibilities by performing several controls. The 13000- and 8000-dalton fragments are not observed if untreated ghosts are carried through the procedures (including NEM protection) used for treated membranes. However, two disulfide reagents, DTNB and 5-[(2-aminoethyl)dithio]-2-nitrobenzoic acid, at the same molar ratio of disulfide to red cells that was used for reaction with II, do give membranes with the same two low molecular weight fragments shown in Figure 6B. It is likely, therefore, that the intramolecular cross-link results from sulfhydryl oxidation rather than from specific cross-linking by a reagent such as II.

Our observation of a cross-link between two subfragments resulting from cleavage at the second, cytoplasmic chymotrypsin site suggests a link between the sulfhydryl of the transmembrane piece and one of the three sulfhydryls in the cytoplasmic portion of the 55000 -dalton fragment. To draw this conclusion, we have to assume that the 13000 -dalton fragment we observe on reducing gels is equivalent to the transmembrane fragment assigned previously (Steck et al., 1976; Rao \& Reithmeier, 1979) as 17000 or 19000 daltons or is derived from it. Our proteolysis conditions differ from the previous ones in employing more $\alpha$-chymotrypsin than used by Steck and a lower temperature than that of Rao and Reithmeier. In addition, new chymotrypsin cleavage sites may be revealed when the intramolecular cross-link is formed. Thus, the fact that we find a slightly smaller peptide (13000 daltons) than the others is neither surprising nor inconsistent with the 13000 -dalton band being a transmembrane subfragment of the 55000-dalton band.

Acknowledgments

We are grateful to Dr. Mitchell Hobisch, Biology De- partment, The Johns Hopkins University, for advice on preparation of hemoglobin from red cells.

Registry No. I, 84130-79-0; II, 84130-83-6; III, 84130-82-5; DTNB, 69-78-3; 4-aminobutyric acid, 56-12-2; cysteamine, 60-23-1.

\section{References}

Antonini, E., \& Brunori, M. (1971) Hemoglobin and Myoglobin in Their Reaction with Ligands, North-Holland Publishing Co., Amsterdam.

Berliner, L. J., Grunwald, J., Hankovszky, H. O., \& Hildeg, K. (1982) Anal. Biochem. 119, 450-455.

Brown, P. A., Feinstein, M. B., \& Sha'af, R. I. (1975) Nature (London) 254, 523-525.

Davoust, J., Schoot, B. M., \& Devaux, P. F. (1979) Proc. Natl. Acad. Sci. U.S.A. 76, 2755-2759.

Defrise-Quertain, F., Chatelain, P., Ruysschaert, J. M., \& Delmelle, M. (1980) Biochim. Biophys. Acta 628, 57-68.

Fairbanks, G., Steck, T. L., \& Wallach, D. F. H. (1971) Biochemistry 10, 2606-2617.

Fowler, V., \& Branton, D. (1977) Nature (London) 268, 23-26.

Freed, J. H. (1976) in Spin Labeling Theory and Applications (Berliner, L. J., Ed.) Vol. 1, Chapter 3, pp 53-132, Academic Press, New York.

Fung, L. W. M. (1981) Biochemistry 20, 7162-7166.

Gaffney, B. J., Willingham, G. L., \& Schepp, R. S. (1983) Biochemistry (preceding paper in this issue).

Hu, C. C., \& Johnson, M. E. (1981) FEBS Lett. 125, 231-234.

Hyde, J. S., \& Thomas, D. D. (1973) Ann. N.Y. Acad. Sci. 222, 680-692.

Koppel, D. E., \& Sheetz, M. P. (1981) Nature (London) 293, 159-161.

Kunitz, M., Anson, M. L., \& Northrop, J. H. (1933) J. Gen. Physiol. 17, 365-373.

Liu, S. C., Fairbanks, G., \& Palek, J. (1977) Biochemistry 16, 4066-4074.

McCalley, R. C., Shimshick, C. J., \& McConnell, H. M. (1972) Chem. Phys. Lett. 13, 115-119.

Nigg, E., \& Cherry, R. J. (1979) Nature (London) 277, 493-494.

Ramjeesingh, M., Grinstein, S., \& Rothstein, A. (1980) J. Membr. Biol. 57, 95-102.

Rao, A. (1979) J. Biol. Chem. 254, 3503-3511.

Rao, A., \& Reithmeier, A. F. (1979) J. Biol. Chem. 254, 6144-6150.

Rosa, J., Benzard, Y., \& Hercules, J., Eds. (1979) Development of Therapeutic Agents for Sickle Cell Disease, North-Holland Publishing Co., Amsterdam.

Shimshick, E. J., \& McConnell, H. M. (1972) Biochem. Biophys. Res. Commun. 46, 321-327.

Staros, J. V., Richards, F. M., \& Haley, B. E. (1975) J. Biol. Chem. 250, 8174-8178

Staros, J. V., Morgan, D. G., \& Appling, D. R. (1981) J. Biol. Chem. 256, 5890-5893.

Steck, T. L. (1978) J. Supramol. Struct. 8, 311-324.

Steck, T. L., Ramos, B., \& Strapazon, E. (1976) Biochemistry 15, 1154-1161.

Thomas, D. D., Dalton, L. R., \& Hyde, J. S. (1976) J. Chem. Phys. 65, 3006-3024.

Walder, J. A., Walder, R. Y., \& Arnone, A. (1980) J. Mol. Biol. 141, 195-216.

Wang, K., \& Richards, F. M. (1974) J. Biol. Chem. 249, 8005-8018.

Wolosin, J. M., Ginsburg, H., \& Cabantchik, Z. I. (1977) J. Biol. Chem. 252, 2419-2427. 